\title{
MULTIPLY YOUR BUSINESS WITH REAL TIME AUTOMATION
}

\author{
Aatmling B. Narayanpure ${ }^{1}$, Sachin M. Nagure ${ }^{2}$ \\ ${ }^{I} P G$ Scholar, Department of Mechanical Engineering, COE, Ambajogai, Maharashtra, India \\ ${ }^{2}$ Asst. Professor Department of Mechanical Engineering, COE, Ambajogai, Maharashtra, India
}

\begin{abstract}
Economic success of equipment and manufacturing companies depends on their ability to produce high quality products at the lowest cost this applies to all, manufacturers have a tough job competing in today's global environment, global competition, price sensitivity, time to market pressures, and increasing complexity all make it very difficult for manufacturers to be successful, that aims to create customize designs as per Engineer To Order (ETO) product, Knowledge based engineering (KBE) has become a practical method of minimizing design cost by design automation and enables you to achieve all of these and more by streamlining repetitive, time consuming mundane tasks and leaving designers more time to focus on innovation, improving product quality, adding value, and winning more business.
\end{abstract}

Keywords: Customize product, Design automation, ETO, KBE, Streamline repetitive task.

\section{INTRODUCTION}

Traditionally, design solid modeling tools are primarily used to design and visualize the artifact as pert heir application needs later the $2 \mathrm{~d}$ drafting is released as production drawings, CAM systems are conventionally used to program machining or cutting instructions on the $\mathrm{CNC} / \mathrm{DNC}$ machines sometimes prototype is created for complex geometry to check the form fit and function, CAE systems are used to check the reliability of the designed artifact (such as structural analysis for stress, thermal, FOS, etc.), this methods tells a designer what the final design looks like but how it has come to be with the help of CAE tools.

Customized products and services is a great competitive differentiator, leading to more sales, higher revenues, increase in customer satisfaction but in other hand all these customize enquiry required special attention from design and hence designers are involved in handling enquiries and creating GA and supporting sales team to prepare quotation, results in less innovation in product design, Knowledge Based Engineering is a tool which captures knowledge from the product life cycle, these knowledge is stored in database and linked to the CAD system.

If changes are required in the design, a new CAD solid model is recreated using some type of computer-aided "redo" or "back-tracking" methods or use of Product Data Management (PDM) backdatedrevision, thesecan be extremely time consuming and costly being that late in the life-cycle process, in such cases a geometry and size solid geometry, configuration changes cannot be handled easily, particularly when parts and dimensions are linked. The power of a "knowledge capture" tool comes from the methods used in capturing the design intent initially so that the anticipated changes can be made easily and quickly later if needed by capturing "design intent" sometime custom software is created as per the need or automation need to speed up the operation. [1]

\section{REQUIREMENT DEFINITION}

It covers all the information relates with product includes, geometry variation, size variable, design logic and calculation, output formats.

\subsection{Geometry Variation}

Geometry variation are related with shape variation, where subassemblies, parts, features are suppress/ unsuppressed as per the requirements, typical geometric variation includes vacuum chamber type as standard / mesh/ with magnetic separator, structural type, drive head, mid support. .

\subsection{Size Input}

User will specify the size input includes, No of Chambers, Tank Height, Tank Length, Tank Width, Customer specification

\subsection{Design Rules and Logic}

All the detail calculation is included in variable table; this includes the analytical, logical, and mechanical or thumb rules, or product knowledge in above format. In traditional approach all the calculation has been done in excel table and for every change in design designer needs to recalculate the required dimension as needed. We are providing all the design calculation to $\mathrm{KBE}$ system so for every change in enquiry all the calculation happens automatically 
Table-1: Variable Table

\begin{tabular}{|c|c|c|c|}
\hline ID & Name & Value & Validation \\
\hline 1 & Tank Width & & SpecificInp \\
\hline 2 & No Of Chember & & \\
\hline 3 & Inlet Height & & Fixed \\
\hline 4 & Std Code & "A061" & Char \\
\hline 5 & Alpha Code & IF(Tank Width=1600, "F",IF(Tank Width=1000,"G","H")) & Char \\
\hline 6 & Depth of Section $\mathrm{H}$ & Section Size & \\
\hline 7 & Width of Flange $B$ & fixed(Depth of Section H) & Fixed \\
\hline 8 & Flange Thk T & fixed(Depth of Section H) & Fixed \\
\hline 9 & Web Thk S & fixed(Depth of Section H) & Fixed \\
\hline 10 & Section Size & $\begin{array}{l}\text { if(and(Tank Width }=1000 \text {, No Of Chember }>=1), 100 \text {, if(and(Tank Width }=1600, \text { No Of } \\
\text { Chember }=1), 100 \text {, if(and(Tank Width }=1600 \text {, No Of Chember }>1), 150,200)) \text { ) }\end{array}$ & \\
\hline 11 & S_FRAME SECTION & if(No Of Chember $>=3.1$, "C CHANNEL","L ANGLE") & DrivenShape \\
\hline 12 & S_CHEMBER NO & if(No Of Chember=1,"SINGLE","MULTIPLE") & Drivenshape \\
\hline 13 & Frame Section Mate Dist & if(s_FRAME SECTION="C CHANNEL",Depth of Section H,50) & \\
\hline 14 & M1 & if(s_FRAME SECTION $=" C$ CHANNEL",50,50) & \\
\hline 15 & M2 & if(s_FRAME SECTION="C CHANNEL",50,0) & \\
\hline 16 & Inlet Height Customer Specific & & \\
\hline 17 & Filter Area & & SpecificInp \\
\hline 18 & Actual Height & $\begin{array}{l}\text { if(s_DIRTY INLET HEIGHT="VEERAJA STANDARD",Inlet Height,Inlet Height } \\
\text { Customer Specific) }\end{array}$ & \\
\hline 19 & front plate length centre to centre & $\begin{array}{l}\text { if(and (Type }=1 \text {, Tank Width }=1600) \text {, (Bottom Frame Length }+315) \text {,if(and }(\text { Type }=1 \text {, Tank } \\
\text { Width }=2000),(\text { Bottom Frame Length+285), (Bottom Frame Length }+240)) \text { ) }\end{array}$ & \\
\hline 20 & Bottom Frame Length & $\begin{array}{l}\text { if(s_VACCUME FILTER TYPE="WITH MESH",(No Of Chember*'1000), (No Of } \\
\text { Chember*1000)+Bottom Frame Constant) }\end{array}$ & \\
\hline 21 & Bottom Frame Width & Tank Width +10 & \\
\hline 22 & Bottom Frame Constant & if(s_VACCUME FILTER TYPE="WITH MESH", 100,75) & \\
\hline 23 & Bottom Frame Pitch & (2)=- & \\
\hline 24 & Offset Dist 1 & if(s_DRIVE POSITION="RH",(Depth of Section $\left.\left.\mathrm{H}^{*} 0.5\right), 40\right)$ & \\
\hline 25 & Offset Dist2 & if(s_DRIVE POSITION="RH",40,(Depth of Section H*0.5)) & \\
\hline 26 & Dia Front & if(s_DRIVE POSITION="RH",88.90,33.70) & \\
\hline 27 & Dia Rear & iff(s_DRIVE POSITION="RH",33.70,88.90) & \\
\hline 28 & Cutout Dist & if(s_VACCUME FILTER TYPE="WITH MESH",500,537.5) & \\
\hline 29 & $\mathrm{X} 1$ & if(No Of Chember $<3.1,0$,if(No Of Chember $<6.1,1075,2075)$ ) & \\
\hline 30 & $\mathrm{XN}$ & ( & \\
\hline 31 & X2 For $\mathrm{L}$ & if(No Of Chember $=1,1075$, if(No Of Chember $=2,2075,3075))$ & \\
\hline 32 & $\mathrm{X} 2$ For $\mathrm{XN}$ & (No Of Chember*1000)- $(2 * \mathrm{XN})$ & \\
\hline 33 & $\mathrm{x} 2$ & if(No Of Chember $<3.1, \mathrm{X} 2$ For L, X2 For XN) & \\
\hline 34 & I Section Depth & fixed(Tank Width) & Fixed \\
\hline 35 & I Section Width & fixed(Tank Width) & Fixed \\
\hline 36 & I Section Web & fixed(Tank Width) & Fixed \\
\hline 37 & I Section Flange & fixed(Tank Width) & Fixed \\
\hline 38 & Type & if(s_VACCUME FILTER TYPE="WITH MESH", 1,0) & Shape \\
\hline 39 & S_CHEMBER NO BOT & $\begin{array}{l}\text { if(and(Type=0,No Of Chember }>2.1 \text { ),"MULTI C",if(and(Type=1,No Of } \\
\text { Chember }>2.1) \text {,"MULTI I",if(and(Type=0,No Of Chember=2)," SINGLE } \\
\text { C",if(and(Type=1,No Of Chember=2),"SINGLE I","NO")))) }\end{array}$ & DrivenShape \\
\hline 40 & Vaccum Brake Tank Widtth W & $\begin{array}{l}\text { if(Type of Vaccum Brake Tank=4450,1500, if(Type of Vaccum Brake } \\
\text { Tank=1000,700,1100)) }\end{array}$ & \\
\hline 41 & Vaccum Brake Tank Length L & $\begin{array}{l}\text { if(Type of Vaccum Brake Tank=4450,2010, if(Type of Vaccum Brake } \\
\text { Tank=2600,2010,1060)) }\end{array}$ & \\
\hline 42 & Brake Tank dist Frm 1 st support & if(Type $=0$, (Position of VBT-X3),Position of VBT) & \\
\hline 43 & Dirty Inlet HT & $\begin{array}{l}\text { if(s_DIRTY INLET HEIGHT="VEERAJA STANDARD",Inlet Height,Inlet Height } \\
\text { Customer Specific) }\end{array}$ & Shape \\
\hline 44 & S_LPATT & if(No Of Chember=3, "Req",'Not Req") & DrivenShape \\
\hline 45 & First dist & $\begin{array}{l}\text { if(Type }=1,1000 \text {, if(and (Type }=0, \text { Tank Width }=1000), 1025 \text {, if(and (Type }=0 \text {, Tank } \\
\text { Width }=1600), 1000,975)))\end{array}$ & \\
\hline & & $\begin{array}{l}\text { if(and(s_VACCUME FILTER TYPE="WITH MESH",No Of Chember >3.1),"C } \\
\text { CUT",if(and(s_VACCUME FILTER TYPE="WITH MESH",No Of }\end{array}$ & I... \\
\hline
\end{tabular}

Table-2: Parametric Equation

\begin{tabular}{|c|c|c|}
\hline Index & Parametric Equation & Parametric Value \\
\hline \begin{tabular}{l|l} 
\\
\end{tabular} & D1@Distance1@STD \& MTD DRIVE HEAD ASSLY NEW.Assembly & Tank Width \\
\hline 3 & $\begin{array}{l}\text { hall width@Sketch1@Drive Head Top Support 2.Part } \\
\text { half tank width@Sketch1@Drive Head Top Support 1.Part }\end{array}$ & $\begin{array}{l}\text { (Tank Width/2)-25 } \\
\text { (Tank Width/2)-25 }\end{array}$ \\
\hline $4 \mid$ & width@Sketch1@Drive Head Top Support 1 For Mesh Part & Tank Width \\
\hline 5 & half of width@Sketch1@Drive Head Top Support1For Mesh.Part & (Tank Width/2)-25 \\
\hline 6 & width@Sketch1@Drive Head Top Support2 For Mesh.Part & Tank Width \\
\hline 7 & half of width@Sketch1@Drive Head Top Support 2 For Mesh.Part & (Tank Width/2)-25 \\
\hline 8 & Len@Sketch1@Extra Support at Base.Part & Tank Width +50 \\
\hline 9 & D3@3DSketch1@Top Frame-1@Bottom Tank GA.SLDASM & $x$ \\
\hline 10 & D3@LPattern2@Top Frame-1@Bottom Tank GA.SLDASM & $x$ \\
\hline 11 & D1@Boss-Extrude1@Bottom Slab and Support_CADEC-1@Bottom Tank GA.SLDASM & Tank Width+100 \\
\hline 12 & D1@LocalLPattern4@Bottom Tank GA.Assembly & No of Chembert1 \\
\hline 13 & D1@Sketch1@TOP FRAME_UPDATED.Part & Tank Width \\
\hline 14 & No@LPattern1@Bottom BT PLate.Part & No Of Chember \\
\hline 15 & D1@Distance10@Bottom Tank GA.Assembly & M1 \\
\hline 16 & O5OHalf LSection@Distance6@Bottom Tank GA.Assembly & M2 \\
\hline 17 & D1@Distance11@Bottom Tank GA.Assembly & M1 \\
\hline 18 & BOTTOMTANKW@Base-Flange1@Left BT Plate.Part & Tank Width+30 \\
\hline 19 & BOTTOM TANK W@Base-Flange1@Right BT Plate.Part & Tank Width +30 \\
\hline 20 & TankWidth plus30@Sketch1@Bottom BT PLate.Part & Tank Width +30 \\
\hline 21 & D1@Sketch1@Support-1@Bottom Tank GA.SLDASM & Tank Width \\
\hline 22 & D2@3DSketch2@Structure Inside-1@Bottom Tank GA.SLDASM & Tank Width \\
\hline 23 & D6@Sketch1@Front BT Plate.Part & front plate length centre to centre \\
\hline 24 & BOTTOM pLATE I@Sketch1@Bootom Frame.Part & Bottom Frame Length \\
\hline 25 & D1@CLPattern1@Bootom Frame.Part & No Of Chember-1 \\
\hline 26 & D1@LPattern2@Bootom Frame.Part & No Of Chember-1 \\
\hline 27 & D1@LPattern3@Bootom Frame.Part & No Of Chember-1 \\
\hline 28 & Hole DiaF@Sketch18@Bootom Frame.Part & Dia Front \\
\hline 29 & Bot Dist Front@Sketch18@Bootom Frame.Part & Offset Dist1 \\
\hline 30 & Half1075@Sketch18@Bootom Frame.Part & Cutout Dist \\
\hline 31 & HoleSize@Sketch2O@Bootom Frame.Part & Dia Rear \\
\hline 32 & Bot Dist@Sketch20@Bootom Frame.Part & Offset Dist2 \\
\hline 33 & Half1075@Sketch20@Bootom Frame.Part & Cutout Dist \\
\hline 34 & D1@Front SideLPattern4@Bootom Frame.Part & No Of Chember \\
\hline 35 & D1@LPattern1@Structure Details-2@Bottom Tank GA.SLDASM & No Of Chember \\
\hline 36 & nol@LPattern2@Structure Details-2@Bottom Tank GA.SLDASM & No Of Chember \\
\hline 37 & D1@LPattern1@Structure Details-1@Bottom Tank GA.SLDASM & No Of Chember \\
\hline 38 & nol@LPattern2@Structure Details-1@Bottom Tank GA.SLDASM & No Of Chember \\
\hline 39 & D1@LPattern1@Structure Details L BackSide-1@Bottom Tank GA.SLDASM & No Of Chember \\
\hline 40 & nol@LPattern2@Structure Details L BackSide-1@Bottom Tank GA.SLDASM & No Of Chember \\
\hline 41 & BOTTOM PLATE I@Sketch1@Bootom Frame-1@Bottom Tank GA.SLDASM & Bottom Frame Length \\
\hline 42 & Widthplus10@Sketch1@Bootom Frame-1@Bottom Tank GA.SLDASM & Tank Width+10 \\
\hline 43 & BF@Sketch11@Bootom Frame-1@Bottom TankGA.SLDASM & Width of Flange $B$ \\
\hline 44 & FT@Sketch11@Bootom Frame-1@Bottom Tank GA.SLDASM & Flange Thk T \\
\hline 45 & Depth@Sketch11@Bootom Frame-1@Bottom Tank GA.SLDASM & Depth of Section $\mathrm{H}$ \\
\hline 46 & TW@Sketch11@Bootom Frame-1@Bottom Tank GA.SLDASM & Web Thk S \\
\hline 47 & BF@Sketch12@Bootom Frame-1@Bottom Tank GA.SLDASM & Width of Flange $B$ \\
\hline 48 & Depth@Sketch12@Bootom Frame-1@Bottom Tank GA.SLDASM & Depth of Section $\mathrm{H}$ \\
\hline 49 & TW@Sketch12@Bootom Frame-1@Bottom Tank GA.SLDASM & Thk $\mathrm{s}$ \\
\hline 50 & D1@Sketch12@Bootom Frame-1@Bottom Tank GA.SLDASM & Flange Thk 7 \\
\hline 51 & D3@LocalLPattern1@Bottom Tank GA.Assembly & $\times 2-\times 21$ \\
\hline 52 & D3@Front SideLPattern4@Bootom Frame.Part & oo \\
\hline 53 & D19@Boss-Extrude2@Bootom Frame-1@Bottom Tank GA.SLDASM & Depth of Section $\mathrm{H}$ \\
\hline
\end{tabular}




\subsection{Parametric Linking}

Both KBE system and SolidWorks are independent software, as all the details of 3D model (Dimension Variable) are captured in the form of (D1@Sketch) in KBE system called as parameter, further we have link those parameter with the variable defined in variable table, once the linking is done any change in enquiry details, user will change the inputs and respective link dimension parameter will modify as per requirements.

\section{DEFINE PRODUCT CLASS}

To configure any product class you must have to open that product class manually or from product class.

To start new configuration, click 'Class', select master model (Assembly Or Part) and click 'OK'. It will ask for database creation for selected product class click 'Yes' to create new one.

\subsection{Crawler}

Crawls into assembly, sub-assembly, parts and captures parts, their features and feature dimensions. The details captured by Crawler are as follows - Part name, subassembly, part or assembly's feature and dimension name.

\subsection{Lock Components}

Locking of part(s) is applicable only for assembly configurator. Locking of part(s) is used when geometry change of some components (parts/sub-assemblies) is not required. (Accessories e.g. Nut, bolts, Bought out items) Procedure to lock parts/subassemblies: Click 'Crawl', a 'Lock Components' window will appear in property manager page which shows list of parts and subassemblies. Check parts or subassemblies to lock them. [6]

\begin{tabular}{|c|c|c|}
\hline$\checkmark x$ & CADECWorks & ? \\
\hline \multicolumn{3}{|c|}{ CADECWorks } \\
\hline \multicolumn{3}{|c|}{ Lock Components } \\
\hline + & $\begin{array}{l}\text { ottom Tank GA } \\
\text { Bottom Tank-1 } \\
\text { Structure Details-1 } \\
\text { Lugs-1 } \\
\text { Structure Details-2 } \\
\text { Structure Details L BackSide-1 } \\
\text { Lugs-2 } \\
\text { Structure Inside-1 } \\
\text { Support-1 } \\
\text { Bottom Frame Assembly-1 } \\
\text { Lugs-5 } \\
\text { Lugs-6 } \\
\text { Top Frame Inclined-2 } \\
\text { Inclined Top Frame For MGS1-1 } \\
\text { Inclined Top Frame For MGS2-1 } \\
\text { T Bracing-1 } \\
\text { Neck Assembly-1 } \\
\text { STD \& MTD DRIVE HEAD ASSLY NEW-1 } \\
\text { 1600 MESH BELT DRIVE HEAD ASSLY -3 } \\
\text { 2000 MESH BELT DRIVE HEAD ASSLY -3 } \\
\text { Bottom Slab and Support_CADEC-1 }\end{array}$ & $\wedge$ \\
\hline
\end{tabular}

Fig- 1: Lock Component

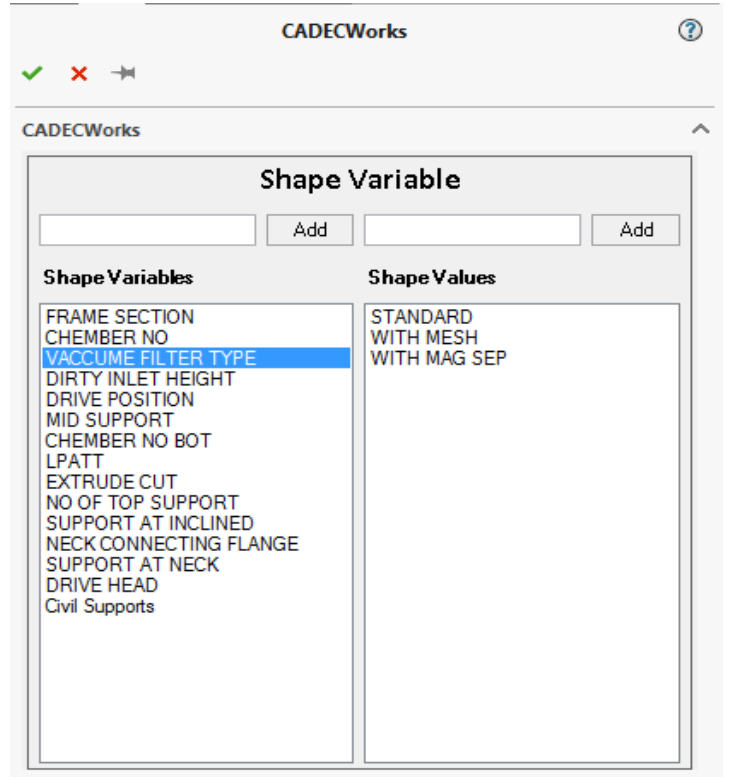

Fig-2: Shape Variation in CADEC

\subsection{Shape Variations}

Shape Variables are independent shape geometry classification possible in the product, Shape Values are different options available for a particular shape variable, to define Shape Variable and Value enter the Shape Variable and value in the text field and Click Add, repeat the procedure for other shape variable and shape value, all the detail calculation is included in variable table; this includes the analytical, logical, and mechanical or thumb rules, or product knowledge in above format. In traditional approach all the calculation has been done in excel table and for every change in design designer needs to recalculate the required dimension as needed. We are providing all the design calculation to KBE system so for every change in enquiry all the calculation happens automatically.

\subsection{Shape Linking}

Shape linking is a method of linking shape values to suppress / unsuppressed subassemblies, parts and partfeatures. After crawling the master assembly, 'Components' palette will show part list in Assembly configurator and in part configurator it will show part name as master model. There are two steps to Linking shape values to master model.

\subsection{Make Mandatory}

Mandatory parts / features are compulsory geometries in the assembly or part. These are always unsuppressed. (The product may/may not have mandatory parts). To make a part mandatory: Right-click on the part, and Click on 'Make Mandatory'.

It is not necessary that all features of the mandatory component are mandatory. Select a mandatory component and tick its mandatory features in the Feature Tree. 


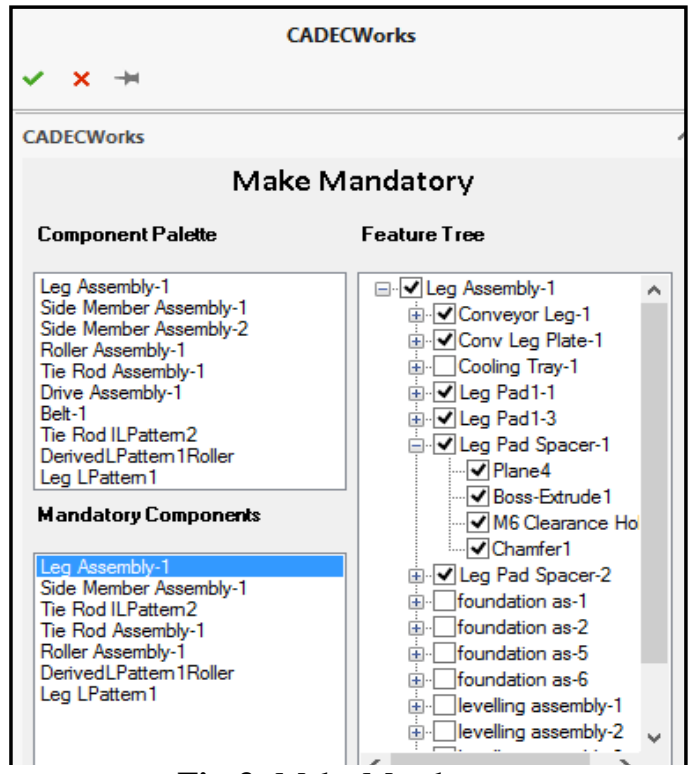

Fig-3: Make Mandatory

\subsection{Make Optional}

Optional parts / features are unsuppressed based on shape variable and shape values chosen. To specify Optional components, you need to choose ashape value first, then choose the optional components one by one and right-click to add the component to 'Optional Components' palette. It is not necessary that all features of the optional component are optional for that shape value. You can select an optional component and tick its optional features in the Feature Tree. [6]

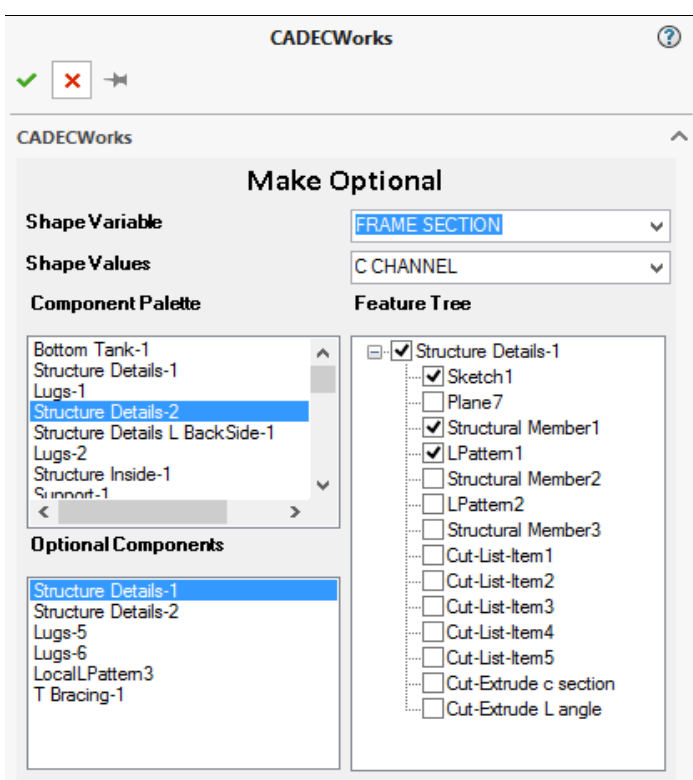

Fig-4: Make Optional

\subsection{Variable Table}

Variable table is a tool for size calculations where you can add variables in structured table format. You can use simple expressions, conditional expressions, logical expressions, functions for validations etc. Image below shows variable table, Define any variable by simply typing its name in the variable table in the Name column. If user starts to enter a variable name and if it starts with "s_" then CADEC gives you the list of all shape variables. The formula can be typed in the value cell or use equation editor for this. To add formula, select the 'Add' Radio button. You need to create equation LHS = RHS in the Equation Editor. You can add any variable to equation editor by clicking on its name in the variable table. [2][6]

\subsection{Size Linking (Parameter Equations)}

Create equation in equation editor by selecting a parameter (from crawler information) on Left Hand Side (L.H.S.) and a variable on Right Hand Side (R.H.S.) When equation editor is in 'Add' mode, you can add any parameter (from crawler info) or variable (from variable table) to equation editor by selecting it. The parameter equation gets added to parameter equations list by clicking Add button, parameter equations on RHS side can also contain variable expression, to delete any parametric equation, and you can Right-click on the equation and select Delete. [6]

\section{DESIGN AUTOMATION OUTPUTS}

User will browse the end user application "Creator" and specifies the enquiry details as following,

\subsection{Instance I-Standard Vacuum Filter}

End user need to fill the enquiry details as input to generate customized model and drawings

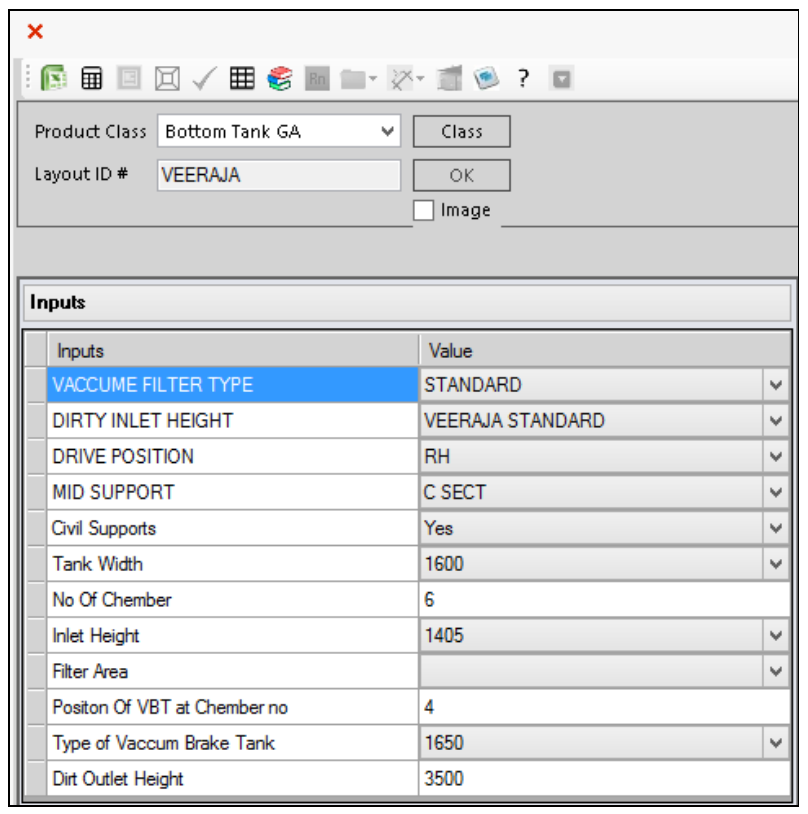

Fig-5: Size Input Screen

\subsection{Model Geometry Output:- Instance I}

Once user click on "Modify" the model geometry is generated as per the enquiry details specified by user. 


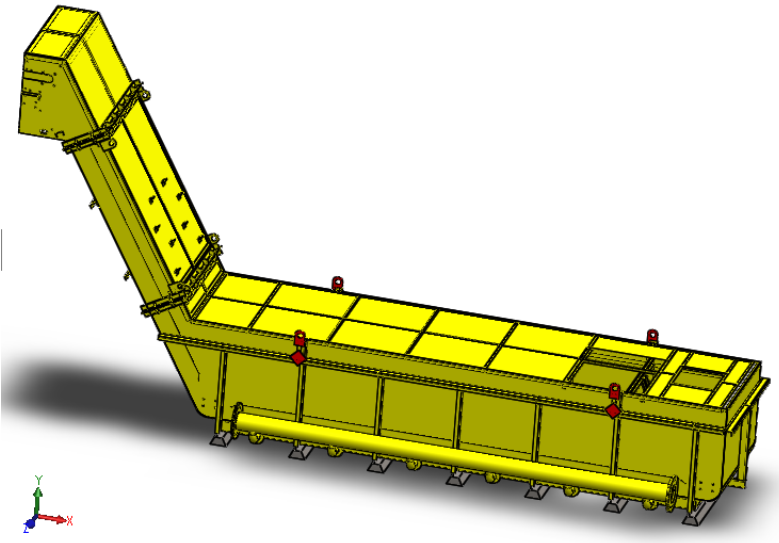

Fig- 6: Vacuum Chambers:-ISO

\subsection{Drawing Output:- Instance I}

Once user click on "Create" the drawing output is generated includes all GA and manufacturing drawings.

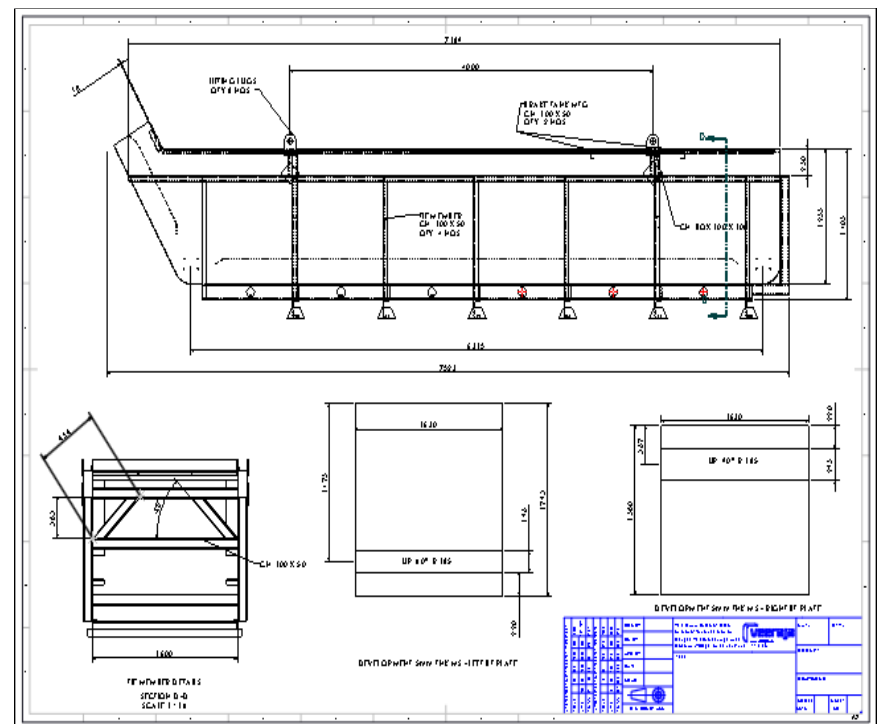

Fig- 7: GA Drawing

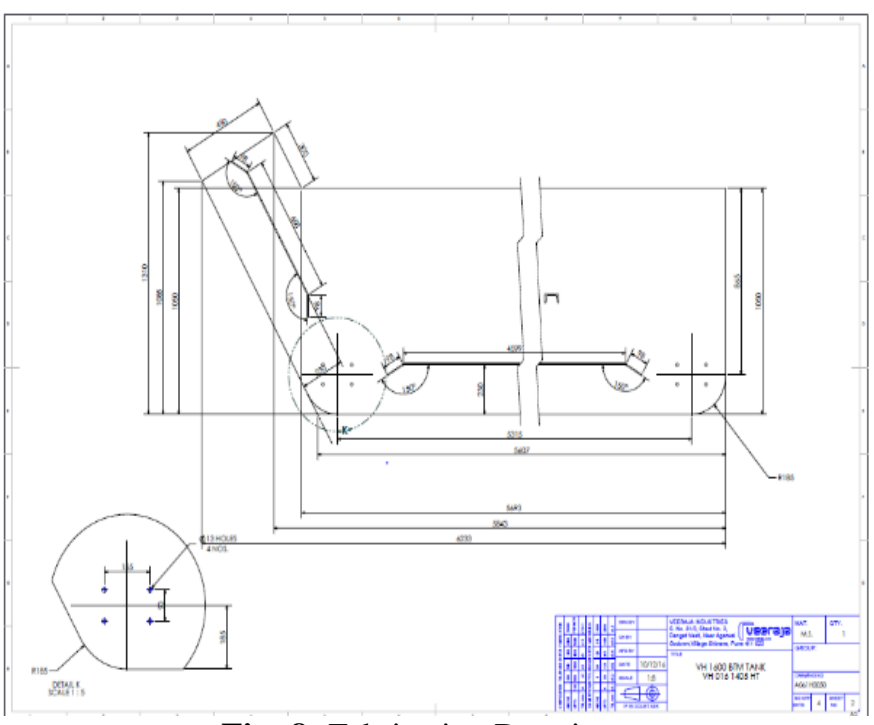

Fig- 8: Fabrication Drawing

\subsection{Instance II-Standard Vacuum Filter}

Start with defining the input details named as typical enquiry details.

\begin{tabular}{|c|c|c|c|}
\hline \multicolumn{4}{|l|}{$x$} \\
\hline \multicolumn{4}{|c|}{ 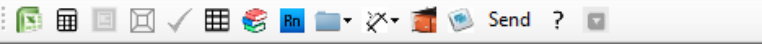 } \\
\hline \multirow{3}{*}{$\begin{array}{l}\text { Product Class } \\
\text { Layout ID \# }\end{array}$} & Bottom Tank GA & Class & \\
\hline & VEERAJA & OK & \\
\hline & & $\square$ Image & \\
\hline \multicolumn{4}{|l|}{ Data } \\
\hline \multicolumn{4}{|l|}{ Inputs } \\
\hline \multicolumn{2}{|l|}{ Inputs } & \multicolumn{2}{|l|}{ Value } \\
\hline \multicolumn{2}{|c|}{ VACCUME FILTER TYPE } & STANDARD & $\checkmark$ \\
\hline \multicolumn{2}{|c|}{ DIRTY INLET HEIGHT } & VEERAJA STANDARD & $\checkmark$ \\
\hline \multicolumn{2}{|c|}{ DRIVE POSITION } & LH & $\checkmark$ \\
\hline \multicolumn{2}{|c|}{ MID SUPPORT } & C SECT & $\checkmark$ \\
\hline \multicolumn{2}{|l|}{ Civil Supports } & No & $\checkmark$ \\
\hline \multicolumn{2}{|l|}{ Tank Width } & 1600 & $\checkmark$ \\
\hline \multicolumn{2}{|c|}{ No Of Chember } & 5 & \\
\hline \multicolumn{2}{|l|}{ Inlet Height } & 1405 & $\checkmark$ \\
\hline \multicolumn{2}{|l|}{ Filter Area } & 1.1 & $\checkmark$ \\
\hline \multicolumn{2}{|c|}{ Positon Of VBT at Chember no } & 2 & \\
\hline \multicolumn{2}{|c|}{ Type of Vaccum Brake Tank } & 1250 & $\checkmark$ \\
\hline \multicolumn{2}{|c|}{ Dirt Outlet Height } & 2500 & \\
\hline
\end{tabular}

Fig-9: Size Input Screen

\subsection{Model Geometry Output:- Instance II}

Once user click on "Modify" the model geometry is generated as per the enquiry details specified by user.

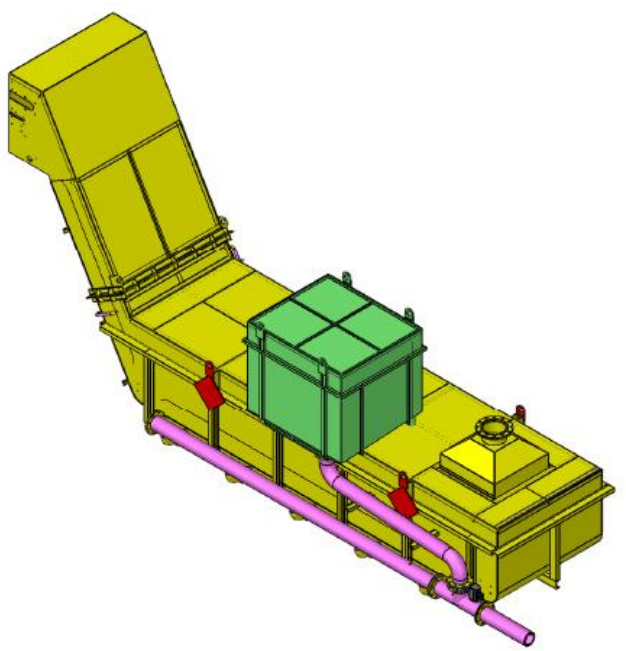

Fig- 10: Vacuum Chambers:-ISO

\subsection{Drawing Output:- Instance II}

To generate the drawings click "Create", this tool enhance with drawing configurator which rescale and rearrange views and dimension as per requirements. 


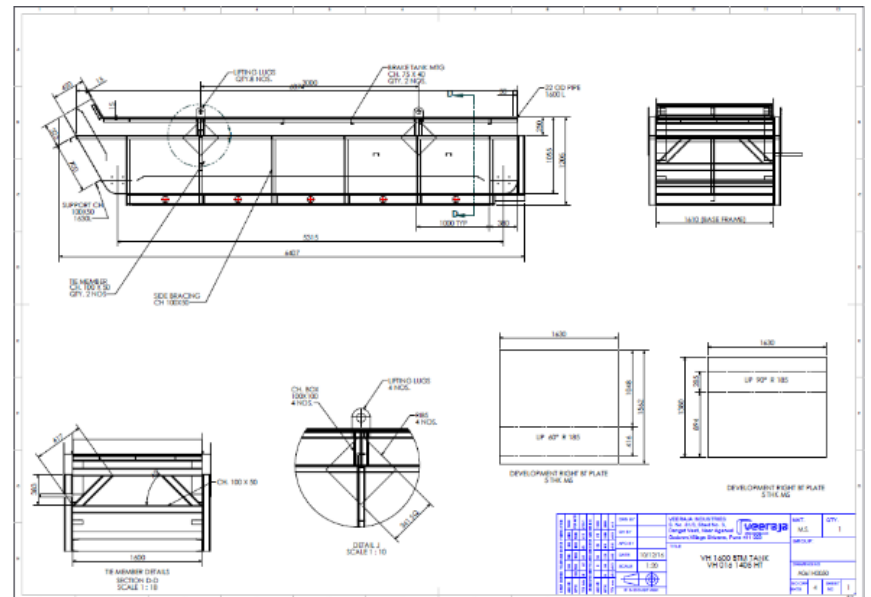

Fig- 11: GA Drawing

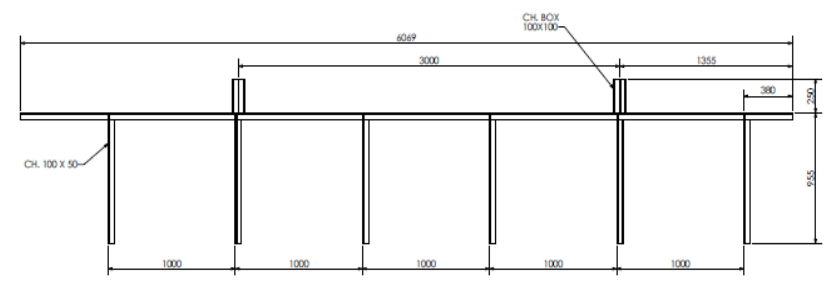

Fig- 12: Fabrication Drawing

\section{CONCLUSION}

This research gives an idea about how CADEC helps manufacturing companies to grow their business with configurable design, each design is customized as per the customer requirements, which leads to more design variation in same product families lead to more business opportunities. Use of CADEC is a template based approach where mechanical engineer can configure their own product family and used by non-technical person so designers can focus on more product innovation than handling mundane task.

$\mathrm{KBE}$ is used in product development to automate mundane task.

Design automation though KBE allows freedom to designer from above routine work so that more time could be used to come up with new innovative solutions.

Automated Process of GA and Manufacturing drawing Reduction in Design time from 5-10 days to 2-3 hours.

\section{ACKNOWLEDGEMENT}

I feel great pleasure in submitting this work "Product Customization through Knowledge Based Engineering"

First of all I would like to take this opportunity to express a deep sense of gratitude and appreciation to my supervisor Prof. S. M. Nagure for his constant support, motivation and continuous encouragement.

I am greatly thankful to Mr. Mandar Parkhi, Director, Mark Design Solutions, Pune, Mr. Pinakin Mate, CEO, Veeraja
Industries, Pune for guiding and authorizing him to use the best possible resources of their organization for his successful completion of the Project study.

Last, but not the least I wish to express my gratitude to God almighty, Parents for their abundant blessings, without which this report would not have been successful.

\section{REFERENCES}

[1] Boart, P., Sandberg, M., Nergård, H. and Isaksson, O. "A knowledge enabled engineering approach for conceptual design of life cycle properties", Journal of Computing and Information Science in Engineering, 1998.

[2] Craig B. and Pinfold M., "The application of a knowledge based engineering approach to the rapid design and analysis of an automotive structure", Advances in engineering software's, 32, pp. 903-912, 1998.

[3] Marcus S., "Knowledge Based Engineering in Product Development", Division of Computer Aided Design Sirius Laboratory, Lulea University of Technology, Sweden, 1997-350.

[4] Marcus S., "Knowledge enabled engineering design tools for manufacturability evaluation ofjet engine components", Division of Computer Aided Design, Department of Applied Physics and Mechanical Engineering, Luleå University of Technology, Sweden,2000.

[5] Gene Daniels, "SolidWorks Essential and Advanced Modeling tools", Year 2017.

[6] Mark Design Solutions “CADECWorks 4.3”, 2016 pp. 20-42, 2016 